\title{
Microbiological Asymmetric Hydroxylation of 7-Carboxybicyclo[2.2.1]heptane and hept-2-ene and Their Methyl Esters Giving Potentially Useful Chiral Synthons for Cyclopentanoids
}

\author{
Yoshimitsu YamaZaKi and Hidekatsu MAEDA \\ Fermentation Research Institute, Agency of Industrial Science and Technology, \\ Ministry of International Trade and Industry, \\ Yatabe-machi Higashi 1-1-3, Tsukuba, \\ Ibaraki 305, Japan
}

Received April 26, 1985

\begin{abstract}
One hundred and nineteen strains of microorganisms (yeasts, bacteria, actinomycetes and fungi) were screened as to the hydroxylation of bicyclo[2.2.1]heptane-7-carboxylic acid, bicyclo[2.2.1]hept-2-ene-7-syn-carboxylic acid, and their methyl esters. Several species belonging to the genera, Bacillus, Streptomyces, Penicillium, Aspergillus, Absidia, Beauveria, Cunninghamella, Drechslera, Mucor and Chaetomium, were found to asymmetrically hydroxylate some or all of the substrates. Bacillus thuringiensis and Aspergillus awamori were the most effective microorganisms for obtaining the chiral products, $(1 R)$-2-hydroxy acids or esters, with enantiomeric purities of $75 \sim 90 \%$ e.e., which are potential intermediates for $(-)$-methyl jasmonate or natural prostaglandins.
\end{abstract}

Bridged ring compounds having a bicyclo[2.2.1] heptane skeleton and appropriate pendant groups are useful precursors for the stereoselective synthesis of various cyclopentanoids. For example, 2-endo-hydroxy-, 2exo-hydroxy- and 2-oxobicyclo[2.2.1]heptane7-anti-carboxylic acid (3a, 4a and 5a) were effectively converted to methyl jasmonate, a perfumery component of jasmin oil. ${ }^{1)} 2$-Endohydroxy-, 2-exo-hydroxy- and 2-oxobicyclo[2.2.1]hept-5-ene-7-anti-carboxylic acid (9a, 10a and 11a) are synthons equivalent to the bicycloheptenone precursors for prostaglandins. $^{2 a, b)}$ When these acids (and their esters) are enantiomerically pure $(1 R)$-isomers, the final products (methyl jasmonate and prostaglandins) can be obtained in the same optically active forms as the natural products through strictly stereoselective synthetic routes. $^{1,2 \mathrm{c})}$ The chiral (1R)-hydroxy compounds $(3,4,9$ and 10) will be formed by regioselective hydroxylation of the parent acids (or esters), $\mathbf{1}$ and $\mathbf{2}$, if reagent(s) or catalyst(s) can differentiate the two prochiral centers, C-2 and C-3 (see formula 1), and the hydroxylation occurs only at $\mathrm{C}-2$. If the other center, C-3, is preferentially hydroxylated, a mirror image of the desired $(1 R)$-enantiomer is formed, leading to the synthesis of methyl entjasmonate or ent-prostaglandins. We decided to use microorganisms as such reagents or catalysts for the asymmetric hydroxylation of 1 and 2. This decision was based on the fact that a bridged ring compound, 3-benzoyl-3azabicyclo[3.3.1]nonane, was asymmetrically hydroxylated by Rhizopus arrhizus. ${ }^{3 a)}$

Microbiological hydroxylation of bridged ring compounds has been studied with natural products (e.g., terpenes with a fenchane, ${ }^{4 b)}$ pinane, ${ }^{4 \mathrm{c})}$ camphane, ${ }^{4 \mathrm{~d}, \mathrm{e})}$ patchoulane ${ }^{4 \mathrm{f})}$ or kaurane $^{4 \mathrm{~g})}$ skeleton, and alkaloids such as codeinone $\left.{ }^{4 \mathrm{~h})}\right),{ }^{4 \mathrm{a})}$ as well as with synthetic compounds such as acylaminotrimethylnorbornane, ${ }^{5 a)}$ aldrin analogues, ${ }^{5 b, 4 a)}$ azabicycloalkanes, $^{3,4 a)}$ adamantanamines ${ }^{5 \mathrm{c}, 4 \mathrm{a})}$ and diamantanols, ${ }^{5 \mathrm{~d})}$ but no work has been report- 

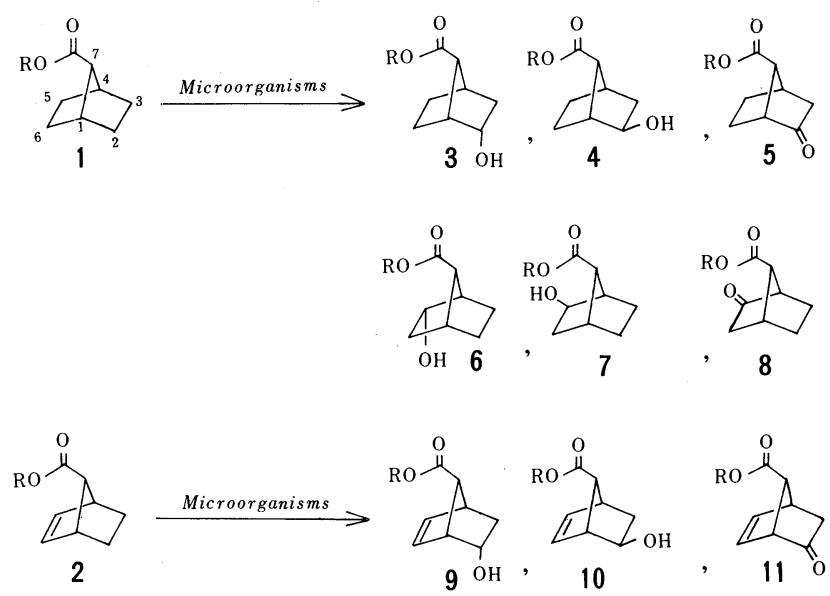

$(1 a \sim 11 a: R=H: 1 b \sim 11 b: R=M e)$

ed on achiral bicyclo[2.2.1]heptanes. Thus, we started this screening work to find microorganisms which can asymmetrically hydroxylate the prochiral bridged ring substrates, $\mathbf{1}$ and $\mathbf{2}$. The microbiological aspects of the work are described in this paper. The chemical aspects (synthesis of authentic specimens and the analytical method for determining the absolute configuration) are described in the succeeding paper. ${ }^{6}$ )

\section{MATERIALS AND METHODS}

Chemicals. The substrates, bicyclo[2.2.1]heptane-7carboxylic acid (1a, mp $73 \sim 75^{\circ} \mathrm{C}$; lit. $\left.{ }^{7)} \mathrm{mp} 74 \sim 75.5^{\circ} \mathrm{C}\right)$ and bicyclo[2.1.1]hept-2-ene-7-syn-carboxylic acid (2a, mp $97 \sim 99^{\circ} \mathrm{C}$; lit. ${ }^{7)} \mathrm{mp} 91 \sim 96^{\circ} \mathrm{C}$ ) were synthesized by carboxylation of 7-bromonorbornane (bp 74.5 $76^{\circ} \mathrm{C} / 20 \mathrm{mmHg}$; lit. ${ }^{8)}$ bp $\left.72 \sim 74^{\circ} \mathrm{C} / 15 \mathrm{mmHg}\right)$ and 7 syn-bromonorbornene (bp $39 \sim 42^{\circ} \mathrm{C} / 4 \mathrm{mmHg} ; \quad$ lit..$^{9)}$ $68 \sim 70^{\circ} \mathrm{C} / 13 \mathrm{mmHg}$ ), respectively, via metallation with lithium $p, p^{\prime}$-di-t-butylbiphenyl. ${ }^{10)}$ The unsaturated acid, 2a, was separated from the by-product 7-anti acid by silica gel column chromatography (ether/hexane) ${ }^{11)}$ Treatment of 1a and 2a with diazomethane gave the respective methyl esters (1b and $\mathbf{2 b}$ ).

Authentic specimens for racemic and (1R)- and/or $(1 S)$ $3 \sim 11$ were stereoselectively synthesized from $( \pm)$ - and (+)- and/or (-)-anti-5-oxotricyclo[2.2.1.0 $\left.{ }^{2,6}\right]$ heptane-3carboxylic acid. Details of the procedure are given in the succeeding paper. ${ }^{6}$ )

Chiral reagents, $(R)-(-)-1-(1-$ naphthyl)ethyl isocyanate (12) and $(R)-(+)-\alpha$-methylbenzylamine (13), were purchased from Aldrich Chemical Co. (Milwaukee, U.S.A.). The optical purities of $\mathbf{1 2}$ and $\mathbf{1 3}$ were $97.7 \%$ e.e. and
$96.2 \%$ e.e., respectively, which was determined by gas chromatographic analysis after derivatization to diastereomers with natural $l$-menthol (for 12) or menthyl chloroformate prepared from $l$-menthol with phosgene ${ }^{12)}$ (for 13).

Yeast, malt and meat extracts, liver infusion, Bacto peptone and agar were obtained from Difco Laboratories (Detroit, U.S.A.). All other reagents were of the best grade available commercially.

Gas chromatography. Shimadzu GC-7A, GC-R1A and GC-9A gas chromatographs equipped with flame ionization detectors and data processors (Shimadzu BPR G-1 or C-R2AX) were used. Packing materials and capillary columns were purchased from Gasukuro Kogyo Inc. (Tokyo, Japan). Packed columns ( $3 \mathrm{~mm}$ i.d. $\times 1.5 \mathrm{~m}$ glass columns packed with chromosorb W AW (80 100 mesh) coated with $5 \%$ SILAR- 5 CP, $5 \%$ SP- 1000 or $15 \%$ cyclohexane dimethanol succinate (CDMS) were used at a carrier $\left(\mathrm{N}_{2}\right)$ flow rate of $60 \mathrm{ml} / \mathrm{min}$ and the following column temperatures: SILAR-5CP, $160^{\circ} \mathrm{C}$; SP-1000 and CDMS, $180^{\circ} \mathrm{C}$. Silica capillary columns containing chemically bonded stationary phases were used, unless otherwise stated, under the following conditions (carrier gas $(\mathrm{He})$ inlet pressure, flow rate and column temperature): $\mathrm{OV}-1$ $(0.25 \mathrm{~mm}$ i.d. $\times 25 \mathrm{~m})-1.0 \mathrm{~kg} / \mathrm{cm}^{2}, 0.86 \mathrm{ml} / \mathrm{min}$ and $120^{\circ} \mathrm{C}$; OV- $1701(0.25 \mathrm{~mm}$ i.d. $\times 25 \mathrm{~m})-1.5 \mathrm{~kg} / \mathrm{cm}^{2}, 1.6 \mathrm{ml} / \mathrm{min}$ and $120^{\circ} \mathrm{C}$; and BP-20 $(0.22 \mathrm{~mm}$ i.d. $\times 25 \mathrm{~m})-1.5 \mathrm{~kg} / \mathrm{cm}^{2}$, $0.87 \mathrm{ml} / \mathrm{min}$ and $175^{\circ} \mathrm{C}$. The retention times of the authentic specimens, $\mathbf{3 b}, \mathbf{4 b}, \mathbf{5 b}, \mathbf{6 b}, \mathbf{7 b}, \mathbf{8 b}, \mathbf{9 b}, \mathbf{1 0 b}$ and $\mathbf{1 1 b}$, were: $8.1,7.1,5.5,6.8,5.1 \sim 9.9,9.3,7.7,7.7$ and $5.6 \mathrm{~min}$ on SILAR-5CP; 6.5, 5.9, 3.1, 5.7, 3.5 4.1, 4.4, 5.7, 6.9 and 3.5 min on SP-1000; 13.4, 12.3, 7.5, 11.9, 10.5, 10.5, 11.4, 12.9 and 7.6 min on CDMS; 12.7, 12.0, 9.8, 12.3, 10.9, $11.7,10.2,10.8$ and $8.6 \mathrm{~min}$ on OV-1; 16.6, 15.3, 11.7, 14.8, $12.5,17.1,13.4,15.0$ and $10.8 \mathrm{~min}$ on OV-1701; and 16.8, $15.4,8.3,14.7,9.2,11.3,14.8,17.7$ and $9.2 \mathrm{~min}$ on BP-20, 
respectively. The peak for $\mathbf{7 b}$ was occasionally broadened or split, especially on polar columns.

Microorganisms and fermentation. Most microorganisms used in this study were obtained from the IFO culture collection (Institute for Fermentation, Osaka) or the IAM culture collection (Institute of Applied Microbiology, Tokyo). Other microorganisms were selected from named cultures which are maintained in our institute. The yeasts and fungi were maintained on potatodextrose-agar ${ }^{13 a}$ ) slants and the bacteria (except for the lactic acid bacteria) and actinomycetes on nutrient agar slants which were prepared with the nutrient medium (see below) supplemented with $2 \%$ agar. The lactic acid bacteria were maintained in $\mathrm{MRS}^{13 \mathrm{~b})}$ stab cultures. These stock cultures (stored at $5^{\circ} \mathrm{C}$ ) were refreshed every halfyear. Liquid cultures were carried out on a test tube shaker $(180 \mathrm{rpm}$; for cultivation in $18 \mathrm{~mm} \times 20 \mathrm{~cm}$ cottonstoppered test tubes) at $30^{\circ} \mathrm{C}$, on a reciprocal shaker (120 rpm; for cultivation in 500-ml cotton-stoppered shaking flasks) at $28^{\circ} \mathrm{C}$, or on a rotary shaker $(170 \mathrm{rpm}$; for cultivation in $500-\mathrm{ml}$ baffle-walled conical flasks with silicon sponge caps) at $30^{\circ} \mathrm{C}$. The medium composition was as follows (per liter of distilled water): for yeasts and fungi-glucose, $10 \mathrm{~g}$; yeast extract, $3 \mathrm{~g}$; malt extract, $3 \mathrm{~g}$; Bacto peptone, $5 \mathrm{~g} ; \mathrm{MgSO}_{4} \cdot 7 \mathrm{H}_{2} \mathrm{O}, 0.3 \mathrm{~g} ; \mathrm{CaCl}_{2} \cdot 2 \mathrm{H}_{2} \mathrm{O}$, $0.1 \mathrm{~g} ; \mathrm{NaCl}, 0.1 \mathrm{~g}$; and rare element solution, $1 \mathrm{ml}$; at $\mathrm{pH}$ 5.6: for bacteria and actinomycetes-yeast extract, $2 \mathrm{~g}$; liver infusion, $2 \mathrm{~g}$; meat extract, $2 \mathrm{~g}$; malt extract, $2 \mathrm{~g}$; glucose, $3 \mathrm{~g}$; glycerol $3 \mathrm{~g}$; Bacto peptone, $5 \mathrm{~g}$; $\mathrm{NaCl}, 3 \mathrm{~g}$; $\mathrm{MgSO}_{4} \cdot 7 \mathrm{H}_{2} \mathrm{O}, \quad 0.3 \mathrm{~g} ; \mathrm{CaCl}_{2} \cdot 2 \mathrm{H}_{2} \mathrm{O}, \quad 0.1 \mathrm{~g} ;$ and rare element solution, $1 \mathrm{ml}$; at $\mathrm{pH}$ 7.4. The composition of the rare element solution was as follows (per liter): $\mathrm{H}_{3} \mathrm{BO}_{3}$, $0.3 \mathrm{~g} ; \mathrm{MnCl}_{2} \cdot 4 \mathrm{H}_{2} \mathrm{O}, 0.2 \mathrm{~g} ; \mathrm{ZnCl}_{2}, 0.75 \mathrm{~g} ; \mathrm{CuSO}_{4} \cdot 5 \mathrm{H}_{2} \mathrm{O}$, $0.2 \mathrm{~g} ; \mathrm{FeCl}_{3} \cdot 6 \mathrm{H}_{2} \mathrm{O}, 2.5 \mathrm{~g} ;\left(\mathrm{NH}_{4}\right)_{6} \mathrm{Mo}_{7} \mathrm{O}_{24} \cdot 4 \mathrm{H}_{2} \mathrm{O}, 0.1 \mathrm{~g}$; and $\mathrm{CoSO}_{4} \cdot 7 \mathrm{H}_{2} \mathrm{O}, 0.15 \mathrm{~g}$. The lactic acid bacteria were cultivated in MRS broth. ${ }^{13 \mathrm{~b}}$

The initial screening procedure. Cells or mycelia of each microorganism ( $8-\mathrm{ml}$ test tube culture of $12 \sim 48 \mathrm{hr}$ old) were collected by centrifugation or filtration, washed with $0.05 \mathrm{M}$ phosphate buffer ( $\mathrm{pH} 7.0$ ), and then mixed with the buffer $(0.2 \mathrm{ml})$ containing $0.1 \% \mathbf{1 a}+0.1 \% \mathbf{1 b}$ or $0.1 \% \mathbf{2 a}+0.1 \% \mathbf{2 b}$ in small vials $(5 \mathrm{~mm} \times 5 \mathrm{~cm})$. The vials were sealed with plastic caps and incubated at $30^{\circ} \mathrm{C}$ for $36 \mathrm{hr}$. The cells or mycelia were removed by centrifugation or filtration. The filtrates or supernatants $(0.3 \sim 0.5 \mathrm{ml})$ were acidified with $2 \mathrm{~N} \mathrm{HCl}$, saturated with $\mathrm{NaCl}$, and then extracted with ether $(1 \mathrm{ml})$. The organic phases were concentrated (by air-drying) and methylated with ethereal diazomethane. The samples were reconcentrated for gas chromatography with packed columns.

The second screening procedure. This experiment was performed on the microorganisms selected in the initial screening. A typical procedure for fungi was as follows. Spores from a stock culture of $A$. niger were inoculated into sterilized medium $(100 \mathrm{ml})$. After shaking for $24 \mathrm{hr}$, the pulpy preculture was inoculated by $15 \mathrm{ml}$ into mediums $(150 \mathrm{ml} \times 8)$ placed in $500-\mathrm{ml}$ cotton-stoppered shaking flasks. Shaking was continued for $24 \mathrm{hr}$. The mycelia were collected by filtration and equally divided into four portions. Each portion was added to autoclaved phosphate buffer $(0.05 \mathrm{M}, \mathrm{pH} 7.5 ; 100 \mathrm{ml})$ containing $3 \%$ glycerol in a $500-\mathrm{ml}$ baffle-walled conical flask with a silicon sponge cap. Four mycelial suspensions were prepared in this way. One of the substrates $(5 \mathrm{mg}$ of $\mathbf{1 a}$ or $\mathbf{2 a}$ dissolved in $1 \mathrm{ml}$ of the buffer and $5.5 \mathrm{mg}$ of $\mathbf{1 b}$ or $\mathbf{2 b}$ dispersed by sonication in $1 \mathrm{ml}$ of the buffer) was added to one of the suspensions. The mixtures were agitated on a rotary shaker $(170 \mathrm{rpm})$ at $30^{\circ} \mathrm{C}$ for $48 \mathrm{hr}$. The mycelia were removed by filtration. Each filtrate was acidified $(\mathrm{pH}$ 1.5) with $6 \mathrm{~N} \mathrm{HCl}$, saturated with $\mathrm{NaCl}$, and then extracted with EtOAc $(150$ and $100 \mathrm{ml})$. The combined organic phases were dried over $\mathrm{Na}_{2} \mathrm{SO}_{4}$, and then concentrated with a rotary evaporator. After methylation with an excess amount of diazomethane, the crude products were chromatographed on silica gel columns (Wako gel C-200, $1 \mathrm{~cm} \times 20 \mathrm{~cm}$ ) with elution with 25 -ml portions of $15 \sim 40 \%$ EtOAc/benzene mixtures. The fractions with $15 \sim 20 \%$ EtOAc/benzene (containing oxo esters) and $25 \sim 35 \%$ EtOAc/benzene (containing hydroxy esters) were separately combined, evaporated to dryness, and then redissolved in $0.2 \mathrm{ml}$ EtOAc. These samples were subjected to gas chromatographic analysis with capillary columns and /or GC-MS analysis. When the desired products were detected, the enantiomeric composition was determined as described in a later section. The same process as above was repeated for other fungi, but with some differences as to the time of cultivation and bioconversion. The times are given in the footnote to Table I. Bacteria and actinomycetes were examined by the following typical procedure. Cells from a stock culture of B. thuringiensis were inoculated into sterilized medium $(100 \mathrm{ml})$. After shaking for $12 \mathrm{hr}$, the preculture was inoculated by $20 \mathrm{ml}$ into mediums $(100 \mathrm{ml} \times 4)$ in 500 - $\mathrm{ml}$ baffle-walled conical flasks and shaken for an additional $7 \mathrm{hr}$. Each substrate (the same amount as above) was separately added to the cultures. Shaking was continued for $49 \mathrm{hr}$ (for bioconversion), and then the cells were removed by centrifugation. The supernatants were acidified (to $\mathrm{pH} 1.5$ ) with $6 \mathrm{~N} \mathrm{HCl}$, saturated with $\mathrm{NaCl}$, and then extracted with EtOAc (150 and $100 \mathrm{ml})$. The extracts were treated in the same way as described for $A$. niger.

Determination of the enantiomeric composition. Hydroxy esters: each sample $(0.1 \sim 0.7 \mathrm{mg}$ of the hydroxy esters) was derivatized with $2 \mu \mathrm{l} \quad(R)-(-)-1-(1-$ naphthyl)ethyl isocyanate (12). The standard reaction procedure is described in the succeeding paper. ${ }^{6}$ ) Oxo esters: a sample $(0.1 \sim 0.15 \mathrm{ml}$ EtOAc solution containing $0.1 \sim 0.2 \mathrm{mg}$ of the oxo esters) was placed in a vial $(8 \mathrm{~mm} \times 5 \mathrm{~cm})$ and the solvent was removed under vaccum. The residue was mixed with $0.1 \mathrm{ml}$ of $6 \mathrm{~N} \mathrm{NaOH}$ and $0.2 \mathrm{ml}$ 
of $\mathrm{MeOH}$, and then the mixture was kept at $30^{\circ} \mathrm{C}$ for $1 \mathrm{hr}$. The content was acidified with $6 \mathrm{~N} \mathrm{HCl}$, saturated with $\mathrm{NaCl}$, and then extracted with ether $(0.5 \mathrm{ml} \times 2)$. The ether layers were transferred to another vial and the solvent was removed under vacuum. The residue was treated with $50 \mu \mathrm{l}$ of thionyl chloride ${ }^{6)}$ and then with $5 \mu$ l of $(R)-(+)-\alpha-$ methylbenzylamine (13) in a mixture of $85 \mu \mathrm{l}$ of toluene and $10 \mu \mathrm{l}$ of pyridine. The diastereomeric derivatives were subjected to gas chromatography under the conditions given in the legend to Fig. 3.

\section{RESULTS}

The initial screening was carried out with microorganisms belonging to the genera given below, where the number of used strains is given in parentheses if more than 1: Saccharomyces (2), Schizosaccharomyces, Rhodotorula, Candida (5), Pichia, Torulopsis, Acetobacter, Leuconostoc, Lactobacillus (2), Bacillus, Acinetobacter, Arthrobacter, Serratia, Pseudomonas (7), Mycobacterium (3), Nocardia (3), Streptomyces (14), Actinomyces (11), Rhizopus (3), Mucor (2), Cunninghamella (2), Absidia, Syncephalastrum, Thamnostylum, Byssochlamys (2), Eurotium, Fennellia, Calonectria, Gibberella (2), Chaetomium (2), Cochliobolus, Tyromyces, Spongiporus, Armillariella, Pycnoporus, Schizophyllum, Lentinus, Penicillium (10), Aspergillus (9), Gliocladium, Beauveria, Cephalosporium, Phialophora, Fusarium (2), Trichoderma, Cladosporium, Drechslera, Aureobasidium, Geotrichum, Alternaria, Verticillium, Trichothecium, Cylindrocarpon, Pellicularia and Corynespora. Among these microorganisms, the following strains were shown to be positive as to the hydroxylation of the substrates (1 and/or $\mathbf{2}$ ) in the gas chromatographic survey: Bacillus thuringiensis IFO 3951, Streptomyces aureofaciens IFO 12594, Streptomyces albofaciens IFO 12833, Rhizopus arrhizus IFO 5780, Mucor pusillus IFO 4578, Cunninghamella blakesleeana IFO 6156, Absidia coerulea IFO 4011, Syncephalastrum racemosum IFO 4814, Thamnostylum piriforme IFO 6117, Gibberella zeae IFO 8850, Chaetomium cochliodes IFO 6308, Chaetomium globosum IFO 4451, Penicillium funiculosum FERM P-8051, Aspergillus niger FERM P-8053, Aspergillus awamori FERM P-
8052, Aspergillus tamarii IFO 4099, Beauveria bassiana IFO 4848, Drechslera sorokiniana IFO 9795, Geotrichum candidum IFO 4597 and Corynespora cassiicola IFO 8160. This suggests that the desired hydroxylating activity is mainly found in molds, especially in molds of the Mucorales and Hyphomycetes, although some species of bacteria and actinomycetes were also active as to this reaction.

In the subsequent screening, twelve strains listed in Table I were selected from among the above strains for their relatively high activity. The bioconversion with each microorganism was carried out on a more expanded scale $(5$ or $5.5 \mathrm{mg}$ ) for each substrate. The time for cultivation and bioconversion (given in the footnote to Table I) and the experimental method (whether resting or fermenting cells were used) were determined taking into account the preliminary results which were obtained with three typical strains, A. awamori, B. thuringiensis and $S$. aureofaciens. In the case of the fungi, a better conversion yield was achieved with mycelia resuspended in a phosphate buffer containing $1 \sim 5 \%$ cosubstrate (e.g., glycerol, xylose or glucose) than with mycelia in the growth medium. 20 35-hr-old mycelia were more active than younger or older mycelia, and shaking for aeration was more effective for the bioconversion than a process lacking any forced aeration. In the case of the bacteria and actinomycetes, the substrate was more effectively converted when added to growing cultures $(6 \sim 7 \mathrm{hr}$ old $)$ than to resting cell suspensions.

The products were extracted with ethyl acetate, methylated with diazomethane as a whole, and partially purified on silica gel columns for examination by gas chromatography using capillary columns and then by gas chromatography-mass spectrometry using a capillary column. Typical gas chromatograms (on OV-1701) are shown in Fig. 1 and examples of mass spectra in Fig. 2. The peaks of the isomers, $\mathbf{4 b}$ and $\mathbf{6 b}$, overlapped each other on the packed columns which were used in the initial screening, but they were separated on the capillary columns. 


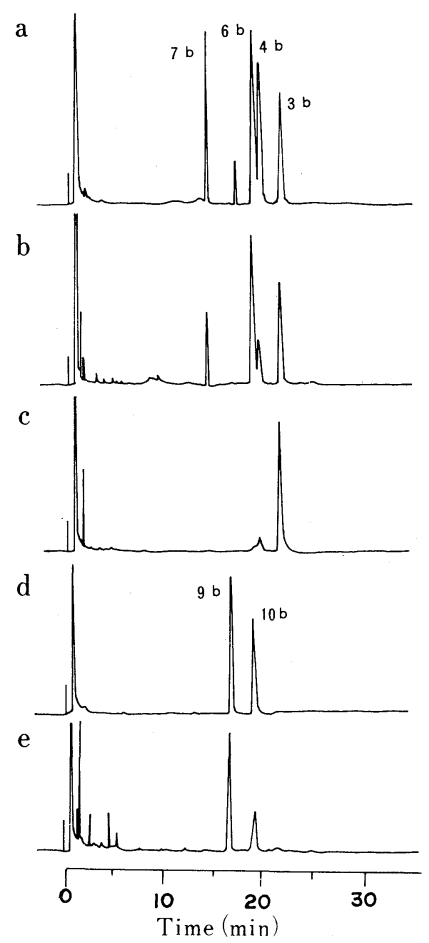

FIG. 1. Gas Chromatograms for the Hydroxy Esters. Samples: a, a mixture of authentic specimens of hydroxy esters $\mathbf{3 b}, \mathbf{4 b}, \mathbf{6 b}$ and $\mathbf{7 b} ; \mathrm{d}$, a mixture of authentic specimens of unsaturated hydroxy esters $9 \mathbf{b}$ and $\mathbf{1 0 b}$; $b$, bioconversion product from $\mathbf{1 b}$ with $C$. blakesleeana; $\mathrm{c}$, bioconversion product from 1a with $A$. niger; and e, bioconversion product from $\mathbf{2 a}$ with $A$. niger. Chromatographic conditions: column, chemically bonded OV-1701 silica capillary column $(0.25 \mathrm{~mm}$ i.d. $\times 25 \mathrm{~m})$; carrier gas, He at an inlet pressure of $2 \mathrm{~kg} / \mathrm{cm}^{2}$ and a flow rate of $2.8 \mathrm{ml} / \mathrm{min}$; column temperature, $110^{\circ} \mathrm{C}$.

The retention time for each bioconversion product was identical to that for the corresponding authentic specimen (methyl ester) on the capillary column used. Its mass spectrum (on GC-MS) was also identical to that of the authentic specimen, although the mass spectra of the stereoisomers (three groups: saturated hydroxy esters, $\mathbf{3 b}, \mathbf{4 b}, \mathbf{6 b}$ and $\mathbf{7 b}$; unsaturated hydroxy esters, $\mathbf{9 b}$ and $\mathbf{1 0 b}$; and oxo esters, 5b and $\mathbf{8 b}$ ) were closely similar within each group. The common major ions for each group can be seen in the typical spectra (Fig. 2). Thus, the bioconversion products were identified as hydroxy or oxo esters, except for their absolute configuration.
It was not revealed in this work whether the product was an acid or ester, since the crude extracts were methylated as a whole for convenience in the screening procedure. However, a preliminary investigation with $A$. awamori and $B$. thuringiensis showed that the acid and ester substrates were converted to acid and ester products, respectively. The amounts of the products were estimated from the peak areas in gas chromatograms (OV-1701) using authentic specimens as standards. The product distribution and conversion yields are given in Table I.

About half of the test strains could hydroxylate both the acids (1a or $\mathbf{2 a}$ ) and the esters (1) or $\mathbf{2 b}$ ), but the remaining half could use only one or other. The product distribution differed not only with the species of microorganism but also with the substrate. From the saturated substrates (1a or $\mathbf{1 b}$ ), anti alcohols (3 and 4) as well as syn alcohols (6 and 7) were usually formed in various endo/ exo ratios (Table I and Figs. $1 \mathrm{~b}$ and $2 \mathrm{a}$ ). More stereoselective hydroxylation was also found in some cases, especially for the acid substrate, as exemplified by $A$. niger (Fig. 1c) and $A$. awamori. These strains dominantly produced the endo anti alcohol (3). The syn exo alcohol (7) was formed only from ester $\mathbf{1 b}$ as the most minor product, except for in the case of $B$. bassiana. The product distribution was narrow for acid $\mathbf{1 a}$ and wide for ester $\mathbf{1 b}$ as substrates. Anti ketone (5) was formed in small amounts with a few of the species (e.g., D. sorokiniana, Fig. 2b), whereas syn ketone (8) was not detected in the extracts. The unsaturated substrates (2a or $\mathbf{2 b})$ were hydroxylated to anti endo and anti exo alcohols (9 and 10), as can be seen in Figs. 1e and 2c for A. niger. No syn products $(6,7$ or 8$)$ wre formed, at least within the limits of detection. This suggests that the double bond of the unsaturated substrates could not be hydroxylated or hydrated by the microorganisms.

The absolute configuration and enantiomeric composition of the products were determined by converting them to diastereomeric derivatives with chiral reagents (12 and 13) 


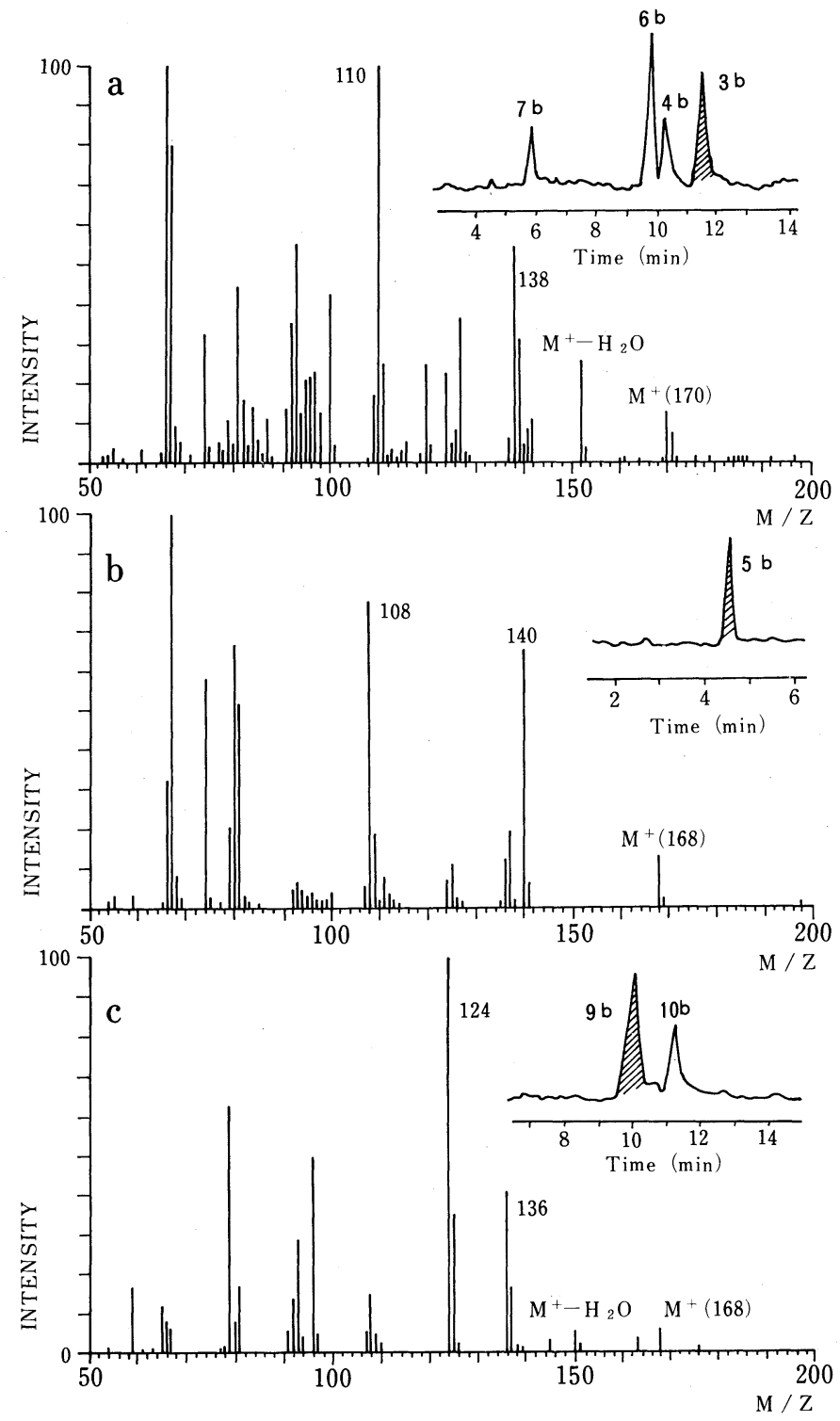

FIG. 2. Analysis of the Methyl Esters of Bioconversion Products by Gas Chromatography-Mass Spectrometry.

Samples: a, hydroxy esters from $\mathbf{1 b}$ with C. blakesleeana: $\mathrm{b}$, oxo ester from $\mathbf{1 b}$ with $D$. sorokiniana; and c, hydroxy esters from 2a with $A$. niger. Each spectrum is the top scan at the crosshatched peak in the accompanying total ion monitor chromatogram presented as an inset. The chromatographic peaks are assigned as shown in the inset, based on their retention times. The mass spectra were measured at an ionization energy of $20 \mathrm{eV}$, and were recorded after subtraction of the background spectrum. Instrument: JEOL JMS-D300 mass spectrometer equipped with a JEOL gas chromatograph and JMA-2000 mass data analysis system. Gas chromatographic conditions: column, chemically bonded BP-20 silica capillary column $(0.22 \mathrm{mmi}$.d. $\times 25 \mathrm{~m})$; carrier gas, $\mathrm{He}$ at an inlet pressure of $1.8 \mathrm{~kg} / \mathrm{cm}^{2}$ and a flow rate of $1.6 \mathrm{ml} / \mathrm{min}$; column temperature, $145^{\circ} \mathrm{C}$. 
Table I. Stereoselectivity in the Microbial Hydroxylation of Bicyclo[2.2.1]heptane-7-Carboxylic Acid (1a) and Its Methyl Ester (1b), AND BiCYCLo[2.2.1]HEPT-2-ENE-7-syn-CARBOXYLIC ACID (2a) AND ITS METHYL EsTER (2b)

\begin{tabular}{|c|c|c|c|c|c|c|c|c|c|c|c|}
\hline \multirow{4}{*}{ Microorganisms $^{a}$} & \multirow{4}{*}{ Substrate } & \multicolumn{6}{|c|}{ Isomer ratio of hydroxylated product $(\%)$} & \multirow{3}{*}{\multicolumn{2}{|c|}{$\begin{array}{c}\text { Enantiomeric } \\
\text { purity }^{b} \\
(\% \text { e.e. })\end{array}$}} & \multirow{3}{*}{\multicolumn{2}{|c|}{$\begin{array}{l}\text { Conversion } \\
\text { yield }(\%)\end{array}$}} \\
\hline & & \multirow{3}{*}{$\begin{array}{l}\text { syn, } \\
\text { exo } \\
(7)\end{array}$} & \multicolumn{3}{|c|}{ from $1 \mathbf{a}$ or $\mathbf{1 b}$} & \multicolumn{2}{|c|}{ from $\mathbf{2 a}$ or $\mathbf{2 b}$} & & & & \\
\hline & & & anti, & syn, & anti, & anti, & anti, & & & & \\
\hline & & & (4) & (6) & (3) & (10) & (9) & $4+3$ & $10+9$ & $7+4+6+3$ & $10+9$ \\
\hline \multirow[t]{2}{*}{ P. funiculosum } & $1 \mathbf{a}, \mathbf{2 a}$ & 0 & 27 & 4 & 69 & 30 & 70 & 81 & 51 & 54 & 4 \\
\hline & $\mathbf{1 b}, \mathbf{2 b}$ & 0 & 47 & 31 & 22 & 90 & 10 & 51 & 49 & 20 & 16 \\
\hline \multirow[t]{2}{*}{ A. niger } & $1 a, 2 a$ & 0 & 8 & 2 & 90 & 22 & 78 & 76 & 54 & 81 & 12 \\
\hline & $1 \mathbf{b}, \mathbf{2 b}$ & 1 & 36 & 6 & 57 & 63 & 37 & 57 & 30 & 20 & 15 \\
\hline \multirow[t]{2}{*}{ A. awamori } & $1 \mathrm{a}, \mathbf{2 a}$ & 0 & $\sim 0$ & $\sim 0$ & $\sim 100$ & 7 & 93 & 86 & 66 & 70 & 40 \\
\hline & $1 b, 2 b$ & 0 & 14 & 5 & 81 & 24 & 76 & 65 & 56 & 22 & 25 \\
\hline A. coerulea & $1 \mathrm{a}$ & 0 & 37 & 23 & 40 & $\mathrm{nf}^{\mathrm{c}}$ & $\mathrm{nf}$ & 2 & $\mathrm{nf}$ & 8 & $\mathrm{nf}$ \\
\hline \multirow[t]{2}{*}{ B. bassiana } & $1 a, 2 a$ & 0 & 2 & 14 & 84 & 15 & 85 & 17 & 41 & $67^{d 1}$ & 7 \\
\hline & $1 b, 2 b$ & 38 & 7 & 9 & 46 & 75 & 25 & 41 & 62 & 20 & 10 \\
\hline \multirow[t]{2}{*}{ C. blakesleeana } & $1 \mathrm{a}$ & 0 & 10 & 60 & 30 & $\mathrm{nf}$ & $\mathrm{nf}$ & 7 & nf & 22 & $\mathrm{nf}$ \\
\hline & $1 b, 2 b$ & 10 & 15 & 41 & 34 & 59 & 41 & 43 & -4 & $53^{d 2}$ & 24 \\
\hline D. sorokiniana & $1 b, 2 b$ & 0 & 56 & 2 & 42 & 82 & 18 & -57 & -32 & $20^{d 3}$ & 28 \\
\hline M. pusillus & $1 b, 2 b$ & 10 & 32 & 33. & 25 & 84 & 16 & 64 & -77 & 74 & 46 \\
\hline C. cochliodes & $1 b, 2 b$ & 2 & 85 & 0 & 13 & 95 & 5 & -11 & 24 & 41 & 16 \\
\hline S. aureofaciens & $1 \mathbf{b}, \mathbf{2 b}$ & 8 & 26 & 44 & 22 & 62 & 38 & -7 & -9 & 39 & 6 \\
\hline S. albofaciens & $1 a, 2 a$ & 0 & 24 & 13 & 63 & 24 & 76 & -52 & 30 & $25^{d 4}$ & 3 \\
\hline B. thuringiensis & $1 b, 2 b$ & 0 & 42 & 4 & 54 & $\sim 100$ & $\sim 0$ & 90 & 76 & $66^{d 5}$ & 19 \\
\hline
\end{tabular}

a The times of preculture, main culture and bioconversion were: 24,25 and $48 \mathrm{hr}$ for $P$. funiculosum; 24,24 and $48 \mathrm{hr}$ for $A$. niger and $A$. awamori; 24,27 and 46 hr for $A$. coerulea and B. bassiana; 48, 26 and $69 \mathrm{hr}$ for C. blakesleeana; 48, 31 and $64 \mathrm{hr}$ for D. sorokiniana; $19,26 \mathrm{and} 42 \mathrm{hr}$ for M. pusillus; $48,26 \mathrm{and} 69 \mathrm{hr}$ for C. cochliodes; 12,7 and $49 \mathrm{hr}$ for $S$. aureofaciens and B. thuringiensis; and $12,8.5$ and $42 \mathrm{hr}$ for $S$. albofaciens, respectively.

$b$ As to $(1 R)$-anti products (as sum of the endo and exo isomers), the values are calculated using peak areas with the equation:

$$
\frac{(R, \text { anti, exo })+(R, \text { anti, endo })-(S, \text { anti, exo })-(S \text {, anti, endo })}{(R, \text { ant } i, \text { exo })+(R, \text { ant } i, \text { endo })+(S, \text { ant } i, \text { exo })+(S, \text { anti, endo })} \times 100,
$$

where, for instance, $(R$, anti, exo $)$ represents the peak area for the diastereomeric derivative of the (1R)-anti exo isomer with chiral isocyanate $\mathbf{1 2}$. The optical impurity of $12(<1.5 \%)$ was neglected in this calculation.

c nf: not found.

${ }^{d}$ Production of anti oxo acid or methyl ester (conversion yield and enantiomeric purity of the ( $1 R$ )-enantiomer): $\mathrm{d} 1,1 \%$ and $83 \%$ e.e.; $\mathrm{d} 2,2 \%$ and $42 \%$ e.e.; $\mathrm{d} 3,4 \%$ and $-85 \%$ e.e.; $\mathrm{d} 4,4 \%$ and $64 \%$ e.e.; and $\mathrm{d} 5,3 \%$ and $93 \%$ e.e. 

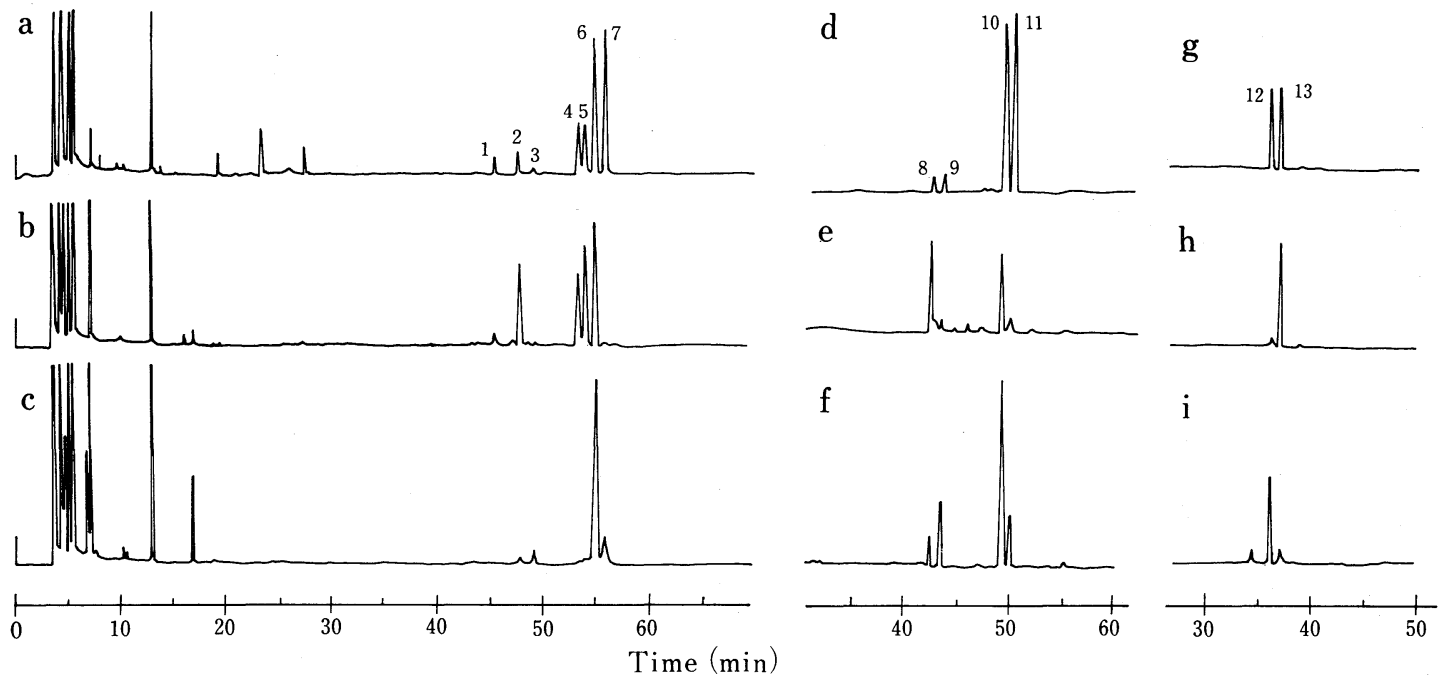

FIG. 3. Gas Chromatograms for the Diastereomers Prepared from the Hydroxy Esters with $(R)-(-)-1-(1-$ Naphthyl)ethyl Isocyanate $(\mathrm{a} \sim \mathrm{f})$ and from the Oxo Acid with $(R)-(+)$ - $\alpha$-Methylbenzylamine $(\mathrm{g} \sim \mathrm{i})$.

Samples (hydroxy esters or oxo acid): a mixture of authentic specimens of racemic $\mathbf{3 b}, \mathbf{4 b}, \mathbf{6} \mathbf{b}$ and $7 \mathbf{b}$ (a) or of racemic $9 \mathbf{b}$ and $\mathbf{1 0 b}(\mathrm{d})$; an authentic specimen of racemic $\mathbf{5 a}(\mathrm{g})$; and bioconversion product from $\mathbf{1 b}(\mathrm{b})$ or $\mathbf{2 b}$ (e) with C. blakesleeana, from $\mathbf{1 a}$ (c) or $\mathbf{2 a}$ (f) with A. niger, from $\mathbf{1 b}$ with $D$. sorokiniana (h), and from 1a with S. albofaciens (i). A chemically bonded OV-1 silica capillary column $(0.25 \mathrm{~mm}$ i.d. $\times 50 \mathrm{~m})$ was used under the following conditions: column temperature, $250^{\circ} \mathrm{C}(\mathrm{a} \sim \mathrm{f})$ or $200^{\circ} \mathrm{C}(\mathrm{g} \sim \mathrm{i})$; carrier gas $(\mathrm{He})$ inlet pressure, $2 \mathrm{~kg} / \mathrm{cm}^{2}$; flow rate, $0.69 \mathrm{ml} / \mathrm{min}(\mathrm{a} \sim \mathrm{f})$ or $0.88 \mathrm{ml} / \mathrm{min}(\mathrm{g} \sim \mathrm{i})$. The numbered peaks in chromatograms a, $\mathrm{d}$ and $\mathrm{g}$ are assigned as the diastereomeric derivatives of: $(1 S)$-7b for peak 1, $(1 R)-\mathbf{7 b}$ and $(1 S)-\mathbf{4 b}$ for peak 2 (overlapping), $(1 R)$-4b for peak 3, $(1 R)$-6b for peak $4,(1 S)$-6b for peak 5, $(1 R)$-3b for peak $6,(1 S)$-3b for peak 7, $(1 S)$-10b for peak $8,(1 R)$-10b for peak $9,(1 R)-9 b$ for peak $10,(1 S)$-9b for peak $11,(1 R)$-5a for peak 12 , and (1S)-5a for peak 13. The basis for the assignments is described in the succeeding paper. ${ }^{6}$ )
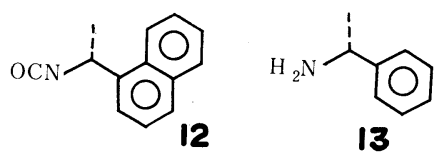

and subsequent separation of the diastereomers by gas chromatography. The two reagents used were the most effective ones for large separation factors for the present compounds, $3 \sim 11$. $^{6}$

Figure $3 \mathrm{a}$ is a gas chromatogram for a mixture of diastereomeric urethanes prepared from authentic hydroxy esters, $\mathbf{3 b}, \mathbf{4 b}, \mathbf{6} \mathbf{b}$ and $\mathbf{7 b}$, with chiral isocyanate $\mathbf{1 2}$. The numbered peaks are assigned as given in the legend to the figure. The peaks for the diastereomers of $(1 R)-\mathbf{7 b}$ and $(1 S)-\mathbf{4 b}$ overlap each other in the chromatogram, but the ratio of each component (and therefore the corresponding peak area) can be roughly calculated by taking into account the relative amounts of $\mathbf{7 b}$ and $\mathbf{4 b}$, determined in another gas chromatogram (e.g., Fig. 1). Figures $3 \mathrm{~b}$ and $3 \mathrm{c}$ are gas chromatograms for the diastereomeric derivatives of the products obtained with $C$. blakesleeana and $A$. niger, respectively. Comparison of Fig. 3b with Fig. 3a shows that the endo anti alcohol (3) produced by $C$. blakesleeana is exclusively composed of the $(1 R)$ enantiomer, whereas the endo syn alcohol (6) is almost racemic. Figure $3 \mathrm{c}$ shows that the $(1 R)$-enantiomer is in excess of the counterpart for the exo anti alcohol (4) as well as for the endo anti alcohol (3) produced by $A$. niger.

The unsaturated hydroxy esters ( $9 \mathbf{b}$ and $\mathbf{1 0 b})$ were also enantiomerically separated by the gas chromatographic method, as shown in Fig. $3 \mathrm{~d}$ (for authentic specimens), 3e (for products with $C$. blakesleeana) and $3 \mathrm{f}$ (for products with $A$. niger). These figures show that the $(1 R)$ - 
enantiomer of the endo alcohol (9) was more preferentially formed than the $(1 S)$ enantiomer by both microorganisms, while the exo alcohol (10) formed by $C$. blakesleeana and $A$. niger was rich in the $(1 S)$ - and $(1 R)$ enantiomer, respectively.

Figures $3 g \sim 3 i$ are the gas chromatograms for the diastereomeric amides prepared by coupling of the anti oxo acid (5a, obtained by hydrolysis of ester $\mathbf{5 b}$ ) with chiral amine $\mathbf{1 3}$. The $(1 S)$-enantiomer was the main stereoisomer of the oxo product with $D$. sorokiniana (Fig. 3h), whereas the $(1 R)$ enantiomer was preferentially formed by $S$. albofaciens (Fig. 3i).

The enantiomeric purity of the $(1 R)$-anti products (the desired compounds as synthons for (-)-methyl jasmonate or natural prostaglandins) was calculated from peak areas in the gas chromatograms. The values including those obtained for other microorganisms are given in Table I.

Asymmetric reactions occurred more or less in all cases. The enantiomeric purity varied with the strain and substrate combination. A noteworthy fact is that when the ratio of the syn products was low (less than $5 \%$ ), the enantiomeric purity of the anti products was high (over $80 \%$ e.e.). Examples are the conversion of 1 a with $P$. funiculosum and $A$. awamori, and the conversion of $\mathbf{1 b}$ with $B$. thuringiensis (Table I). This suggests that high stereoselectivity toward the anti side (C-2 and $\mathrm{C}-3)$ might be a prerequisite for the predominant formation of one of the hydroxy enantiomers. On the other hand, the endo/exo stereoselectivity seemed to be unrelated to the enantiomeric purity of the anti products. The value for the conversion of $\mathbf{1 b}$ with $B$. thuringiensis reached $90 \%$ e.e., although the ratio of the exo and endo alcohols was approximately $4: 5$. On the contrary, the exo/endo ratio for the anti products with $C$. cochliodes was high $(6.5: 1)$, but the enantiomeric purity was low. In the case of the unsaturated substrates, the endo/exo stereoselectivity as well as the absolute stereoselectivity generally paralleled the results for the saturated substrates. A remarkable exception was $B$. thuringiensis, which produced little endo alcohol (9) from unsaturated substrate $\mathbf{2 b}$. The enantiomeric purity of the oxo product was higher than those of the hydroxy products (the expected precursors of the oxo product) in three cases of B. bassiana, D. sorokiniana and B. thuringiensis. This suggests that the succeeding enzyme reaction may have led to enantiomerical enrichment.

\section{DISCUSSION}

Monohydroxylation at the secondary carbons of 7-substituted bicyclo[2.2.1]heptanes and heptenes possibly gives 8 and 4 isomeric alcohols as illustrated below. If the reaction
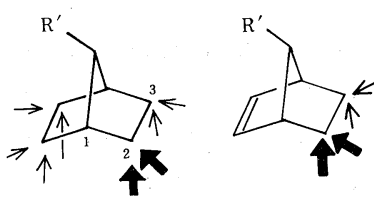

occurs at C-2 (as indicated by bold arrows), chiral $(1 R)$-anti alcohols are obtained, which are desired as synthons for naturally occurring methyl jasmonate and prostaglandins.

The product distribution and the enantiomeric purity of the anti products (Table I) reflect the regioselectivity in the microbial hydroxylation. The regioselectivity was considerably high in two cases: the conversion of $\mathbf{1 a}$ with $A$. awamori and the conversion of $\mathbf{1 b}$ or 2b with $B$. thuringiensis. With these microorganisms, the $(1 R)$-anti products were dominantly formed through hydroxylation of the prochiral substrates. Thus, it has been shown that biological systems (e.g., enzymes) can differentiate between the left $(\mathrm{C}-2)$ and the right (C-3) of the symmetrical bicyclo[2.2.1]heptane skeleton and can effect asymmetric synthesis of $(1 R)$-hydroxy compounds.

The regioselectivity was, however, poor in many cases. Two interpretations are possible: (1) the enzyme for the microbiological hydroxylation can bind the substrates in various orientations at its active site, and therefore more than one product is formed; or (2) in 
each microorganism more than one enzyme hydroxylates the substrate, and the stereoselectivities of the enzymes are different from each other. At present, nothing can be concluded in this respect. It seems unlikely that the enzyme(s) for this hydroxylation developed during the course of evolution so as to be best for the present bicycloheptane substrates, because they are artificial compounds and even naturally occurring homologues (e.g., borneol and camphor) were not utilized in the screening. The test strains (119 strains) were chosen in an almost completely random way. Therefore, the finding of the highly stereoselective hydroxylation with $A$. awamori and B. thuringiensis must be considered to be a matter of chance. However, the high rate $(2 / 119)$ has encouraged us to screen further microorganisms by the present method to select more useful strains for the asymmetric synthesis.

Microbiological hydroxylation has been widely used for stereoselective synthesis or transformation of steroids, ${ }^{14 a, b)}$ terpenes, ${ }^{4 a)}$ alkaloids, ${ }^{4 a, 14 b)}$ hydrocarbons and the like. ${ }^{4 a}$, 14c) Most work has concerned the diastereo differentiating reaction ${ }^{15)}$ with chiral molecules (naturally occurring substrates) or the enantiomer differentiating reaction ${ }^{15)}$ with racemic compounds (synthetic substrates). Another type of asymmetric reaction is the enantio differentiating reaction ${ }^{15}$ with achiral (or prochiral) substrates. The present hydroxylation is of this latter type. A small number of earlier works in this field have shown the formation of optically active products, such as: $(S)-{ }^{16)}$ and $(R)-3$-hydroxy-2methylpropionic acid ${ }^{17)}$ from isobutyric acid, $(+)$-2-cyclohexenol from cyclohexene, ${ }^{18)}(S)$ 2 -hydroxy- $\beta$-ionone from $\beta$-ionone, ${ }^{19)}(-)$-cinerolone from cinerone, ${ }^{20)}(+)-2-(4-h y d r o x y-$ 1-oxocyclopent-2-ene)heptanoic acid from 2(1-oxocyclopent-2-ene)heptanoic acid, ${ }^{21)}$ and the chiral azabicyclononanol ${ }^{3 a)}$ mentioned earlier. Enantio differentiating hydroxylation with microorganisms plays an important role in asymmetric synthesis, because such a reaction with ordinary organic reagents is still very difficult even with modern organic chem- istry. The present results will provide useful information for the application of microorganisms to the field of asymmetric synthesis. Preparation of optically active $\mathbf{3 a}$ with $A$. awamori and optically active 11a through hydroxylation with $B$. thuringiensis will be described elsewhere. ${ }^{22)}$

\section{REFERENCES}

1) S. Torii, H. Tanaka and T. Mandai, J. Org. Chem., 40, 2221 (1975).

2) (a) E. J. Corey, T. Ravindranathan and S. Terashima, J. Am. Chem. Soc., 93, 4326 (1971); (b) E. D. Brown, R. Clarkson, T. J. Leeney and G. E. Robinson, J. Chem. Soc., Chem. Commun., 642 (1974); (c) J. S. Bindra and R. Bindra, "Prostaglandin Synthesis," Academic Press, Inc., New York, 1977.

3) (a) R. A. Johnson, H. C. Murray and L. M. Reineke, J. Org. Chem., 34, 3834 (1969). (b) A. Archelas and C. Morin, Tetrahedron Lett., 25, 1277 (1984). (c) A. Archelas, R. Furstoss, B. Waegell, J. LE Petit and L. Deveze, Tetrahedron, 40, 355 (1984).

4) (a) K. Kieslich, "Microbial Transformations of NonSteroid Cyclic Compounds," Georg Thieme Publishers, Stuttgart, 1976; (b) B. Pfrunder and Ch. Tamm, Helv. Chim. Acta, 52, 1643 (1969); (c) P. K. Bhattacharyya, B. R. Prema, B. D. Kulkarni and S. K. Pradhan, Nature, 187, 689 (1960); (d) M. S. Allen, N. Darby, P. Salisbury, E. R. Sigurdson and T. Money, Can. J. Chem., 57, 733 (1979); (e) S. Banerjee and G. Dec, Biochem. Biophys. Res. Commun., 88, 833 (1979); (f) H. Hikino, K. Aota, Y. Tokuoka and T. Takemoto, Chem. Pharm. Bull., 16, 1088 (1968); (g) E. L. Ghisalberti, P. R. Jefferies, M. A. Sefton and P. N. Sheppard, Tetrahedron, 33, 2451 (1977); (h) M. Yamada, K. Iizuka, S. Okuda, T. Asai and K. Tsuda, Chem. Pharm. Bull., 10, 981 (1962).

5) (a) M. E. Herr, H. C. Murray and G. S. Fonken, J. Med. Chem., 14, 842 (1971); (b) I. Schuphan and K. Ballschmiter, Nature, 237, 100 (1972); (c) M. E. Herr, R. A. Johnson, H. C. Murray, L. M. Reineke and G. S. Fonken, J. Org. Chem., 33, 3201 (1968); (d) H. Lipavská, L. Vodička, J. Burda, J. Třiska, V. Krumphanzl, Z. Vaněk and M. Podojil, Biotechnol. Lett., 4, 563 (1982).

6) Y. Yamazaki and H. Macda, Agric. Biol. Chem., in press (1986).

7) R. R. Sauers and R. M. Hawthorne, Jr., J. Org. Chem., 29, 1685 (1964).

8) A. P. Marchand and W. R. Weimar, Jr., Chem. Ind., 200 (1969).

9) H. Kwart and L. Kaplan, J. Am. Chem. Soc., 76, 4072 (1954)

10) J. Stapersma and G. W. Klumpp, Tetrahedron, 37, 
187 (1981).

11) J. K. Kochi, P. Bakuzis and P. J. Krusic, J. Am. Chem. Soc., 95, 1516 (1973).

12) R. G. Annett and P. K. Stumpf, Anal. Biochem., 47, 638 (1972).

13) (a) "American Type Culture Collection, Catalogue of Strains I," 15th Edition, American Type Culture Collection, Rockville, 1982, p. 605; (b) K. Yamasato, "Biseibutsu no Hozon-ho (The Preservation of Microorganisms)," ed. by T. Nei, University of Tokyo Press, Tokyo, 1977, p. 180.

14) (a) D. Perlman; C. J. Sih and J. P. Rosazza, "Applications of Biochemical Systems in Organic Chemistry. Part I," ed. by J. B. Jones, C. J. Sih and D. Perlman, John Wiley \& Sons, New York, 1976, p. 47 and p. 69; (b) H. Iizuka and A. Naito, "Microbial Conversion of Steroids and Alkaloids," University of Tokyo Press, Tokyo, 1981; (c) G. K. Skryabin and L. A. M. Golovleva, "Microorganisms in Organic Chemistry," Nauka, Moscow, 1976; Japanese edition: "Biseibutsu ni Yoru Yukikagobutsu no
Henkan," translated under the supervision of $\mathrm{S}$. Fukui, Gakkai Shuppan Center, Tokyo, 1980.

15) M. Nakazaki, "Fusei Han-no no Kagaku (Chemistry of Asymmetric Reaction)," ed. by The Chemical Society of Japan, University of Tokyo Press, 1974, p. 1.

16) C. T. Goodhue and J. R. Schaeffer, Biotechnol. Bioeng., 13, 203 (1971).

17) J. Hasegawa, M. Ogura, H. Kanema, N. Noda, H. Kawaharada and $\mathrm{K}$. Watanabe, J. Ferment. Technol., 60, 501 (1982).

18) P. K. Bhattacharyya and K. Ganapathy, Ind. J. Biochem., 2, 137 (1965) [C.A., 64, 8673c (1966)].

19) Y. Mikami, E. Watanabe, Y. Fukunaga and $T$. Kisaki, Agric. Biol. Chem., 42, 1075 (1978).

20) B. Tabenkin, R. A. LeMahieu, J. Berger and R. W. Kierstead, Appl. Microbiol., 17, 714 (1969).

21) S. Kurozumi, T. Toru and S. Ishimoto, Tetrahedron Lett., 49, 4959 (1973).

22) Y. Yamazaki and H, Maeda, Agric. Biol. Chem., submitted for publication (1985). 